\title{
The influence of health-seeking behavior on the incidence and perinatal outcome of umbilical cord prolapse in Nigeria
}

This article was published in the following Dove Press journal:

International Journal of Women's Health

30 June 2010

Number of times this article has been viewed

\section{Christopher A Enakpene' Akin-Tunde O Odukogbe ${ }^{3}$ Imran O Morhason-Bello ${ }^{2}$ Akinyinka O Omigbodun ${ }^{3}$ Ayo O Arowojolu ${ }^{3}$}

'SUNY Downstate Medical Center, Brooklyn, New York, USA; ${ }^{2}$ Department of Obstetrics and Gynecology, University College Hospital, Ibadan, Nigeria;

${ }^{3}$ Department of Obstetrics and Gynecology, College of Medicine, University of Ibadan, Nigeria and University College Hospital, Ibadan, Nigeria
Correspondence: Christopher A Enakpene Department of Obstetrics and Gynecology, State University of New York Downstate Medical Center 450 Clarkson Avenue, Brooklyn New York I I 203, USA Tel +l 3477507035

Email christdew2002@gmail.com
Objectives: To determine the influence of health-seeking behavior of urban women in South-West Nigeria on the incidence and perinatal outcome of umbilical cord prolapse (UCP).

Methods: A retrospective study comparing two groups of urban women using information extracted from medical records of patients who had UCP, and were managed at the University College Hospital Ibadan, Nigeria from January1st 1995 to December 31st 2005. The data was analyzed using SPSS software (version 15). Analysis included simple tabulation, proportion and comparison of incidence, perinatal morbidity, and mortality of UCP between the two groups of women using Chi-square or Fisher's exact test. Odds ratio (OR) and 95\% confidence intervals (CI) were calculated whenever necessary. $P$-value of 0.05 or less was statistically significant. Results: Women without prenatal care were more likely to have fetuses with UCP (54, 75\%), than in women who had prenatal care $(18,25 \%)$. The risk of perinatal death from UCP was higher in women without prenatal care, as compared with those who received prenatal care (OR $3.02,95 \% \mathrm{CI}$ : 0.879 to $10.356 ; P$-value $=0.061$ ). The risk of perinatal morbidity and neonatal intensive care admission was also higher among women without prenatal care as compared with women who received prenatal care (OR 4.09, 95\% CI: 1.03 to $16.30 ; P$-value $=0.041)$. The overall perinatal mortality rate in the study population was 403 per 1000 total births, and this was five times more than that of the hospital perinatal mortality rate of 80 per 1000 total births during the study period. The perinatal mortality rate was higher among women without prenatal care, 463 per 1000 total births, as compared with 222 per 1000 total births in women who received prenatal care. Perinatal death before arrival at the hospital is less likely to occur in women with prenatal care when compared with women without prenatal care (OR 0.0635; 95\% CI: 0.0052 to $0.776 ; P$-value $=0.03$ ).

Conclusion: A high index of suspicion and an identification of risk factors, with early diagnosis, prompt intervention, and provision of health care facilities can reduce the incidence and poor outcome of UCP in developing countries.

Keywords: prenatal care, incidence, apgar scores, perinatal morbidity, perinatal mortality

\section{Introduction}

The umbilicus forms a major connection between the fetus and the placenta. It plays a major role in the exchange of nutrients, gases, and metabolites between the mother and the fetus.

Prolapse of the umbilical cord is a condition in which the umbilical cord lies beside or below the presenting part following rupture of the fetal membranes. ${ }^{1,2}$ It is called cord presentation when the fetal membranes are still intact. ${ }^{1,2}$

Umbilical cord prolapse (UCP) is a rare obstetric emergency with life-threatening consequences to the fetus. It can result in serious obstetric complications that 
significantly affect fetal health. The outcome of UCP is highly dependent on the speed and appropriateness of the intervention offered. ${ }^{3}$ The risks to the mother often arise as a result of problems associated with the kind of intervention, such as cesarean section, used to rescue the baby. ${ }^{4}$ There is, however, an increase risk of fetal brain damage or death arising from acute hypoxia in cases of UCP, with a perinatal mortality rate of $9 \%$ to $49 \%{ }^{5,6}$ Having said that, the perinatal mortality rate associated with cord presentation is however slightly lower than in UCP.,

The incidence of cord prolapse has remained unchanged over a period of years, varying from $0.20 \%$ to $0.50 \%$, or 1 in 200 to 1 in 500 deliveries. However, the perinatal mortality rate has fallen to between 36 and 162 per 1000 births within the past few decades, due to immediate delivery by cesarean section and improved neonatal intensive care facilities. ${ }^{1,8,9}$ Unfortunately, there is still a significantly higher rate of perinatal mortality in developing countries, as compared with developed countries, as a result of poor obstetric care and utilization of available health facilities.

The etiology of cord prolapse is usually multifactorial, ${ }^{10,11}$ however breech presentation is the commonest single cause, accounting for $40 \%-50 \%$ of cases, especially flexed breech. ${ }^{10,12}$ Apart from breech presentation, other conditions that interfere with close application of the presenting part to the lower segment of the uterus and the pelvic brim also predispose to cord prolapse. ${ }^{13,14}$ These conditions include prematurity $<37$ weeks; low birth weight $<2.5 \mathrm{~kg}$; transverse, oblique, and unstable lie; congenital abnormality of the uterus and pelvis; multiple pregnancy, especially the second twin; low placenta and other abnormal placentations; polyhydramnios; and uterine fibroids. ${ }^{1,13}$ lack of close application of the presenting part can also result from obstetric manipulations such as external cephalic version, internal podalic version of the second twin, manual rotation, placement of a intrauterine pressure catheter and artificial rupture of membranes with an unengaged presenting part, amniotomy, abnormality of the umbilical cord, fetus of male gender, and fetal hypotonia. ${ }^{13}$

There are two types of UCP: overt and occult UCP. In overt cord prolapse, the cord is beyond the fetal presenting part and the fetal membranes are invariably ruptured. However, in occult UCP, the cord is alongside, but not past, the fetal membranes, which are either ruptured or intact. Perinatal morbidity and mortality in cord prolapse occurs as a result of compression of the umbilical cord by the presenting part and/or spasm of the cord vessels due to drop in temperature between intrauterine and extravaginal environment; ${ }^{9}$ hence the need to prevent cord compression by the presenting part, and also replacement of the cord within the vagina before definitive management. ${ }^{15,16}$ Immediate delivery is the ideal if the fetus is alive and sufficiently mature as fetal survival depends on the time interval between diagnosis and delivery. ${ }^{17-21}$ Measures that can be taken before delivery include immediate resuscitative intervention (such as calling for assistance); venous access; minimal handling of the cord outside the vagina to prevent vasospasm (including the use of surgical packs soaked in warm saline); elevating the presenting part manually, or by instilling 500-750 $\mathrm{mL}$ of saline to prevent cord compression; and changing maternal position to knee-chest or a head-down tilt, preferably in left-lateral position. Excessive displacement of the presenting part may encourage more cord prolapse. ${ }^{15-17}$ Removal of the hand once the presenting part is above the pelvic brim and applies continuous suprapubic pressure. Tocolysis can be considered while preparing for cesarean section if there are persistent fetal heart rate abnormalities despite attempts to prevent compression mechanically, and when delivery is likely to be delayed.

The justification for this study is borne out of the observation of increasing utilization of alternative unorthodox obstetric services among pregnant urban women in Nigeria, such as mission homes, and the associated obstetric sequelae. Most of the catastrophic obstetric complications that are observed occur among this group, primarily as a result of failing to arrive early enough at the hospital to seek appropriate intervention. Most of the leading causes of both maternal and perinatal morbidity and mortality need early diagnosis, along with prompt and appropriate intervention. UCP falls into this category of requiring prompt delivery in order to successfully salvage the baby. In light of this, a retrospective study was conducted in order to determine the influence of prenatal care and health-seeking behaviors on the incidence and perinatal outcome of UCP.

\section{Materials and methods}

This is a tertiary hospital based retrospective study designed to determine how health-seeking behavior affects the incidence and the perinatal outcome of UCP in South West Nigeria.

The study period was from January 1, 1995 to December 31,2005 , covering 78 cases of UCP that were seen at the University College Hospital, Ibadan, Nigeria. Six cases were excluded from the analysis because the medical records contained inadequate information.

Information of the remaining 72 cases of UCP was obtained from the labor and delivery register and the relevant 
case notes retrieved from the hospital medical records. Adequate prenatal care was defined as consisting of at least four prenatal visits in the index pregnancy and/or at least one prenatal visit within the 2-4 weeks preceding the occurrence of UCP. Inadequate prenatal, or no prenatal care, is defined as poor compliance with prenatal clinic visits or nonattendant at the prenatal clinic in the four weeks preceding occurrence of cord prolapse. Data such as age, prenatal care status, mode of delivery, and perinatal outcomes, Apgar scores, admission to neonatal intensive care unit, and timing of perinatal death were obtained and entered into a computer running Statistical Package for Social Science (Version 15 for Windows; SPSS Inc. Chicago, IL, USA). These were analyzed using simple tabulations and proportions. Comparison of the incidence of UCP and perinatal morbidity and mortality between women who received adequate prenatal care, and women who did not, were determined using Chi-square and Fisher's exact test. Odds ratio (OR) at 95\% confidence intervals (CI) was calculated to determine the impact of utilization of prenatal care facilities on the incidence and perinatal morbidity and mortality of UCP. $P$-values less than or equal to 0.05 were adduced as statistically significant.

\section{Results}

During the study period there were 16,566 deliveries in this hospital, and 78 cases of UCP were managed, giving a crude incidence rate of $0.47 \%$, or 1 in 212 deliveries.

Table 1 shows age group distribution and prenatal care status of patients presenting with UCP from 1995 to 2005 at the University College Hospital, Ibadan, Nigeria. It shows that the age of the patients varied between 15 years and 40 years, and that the highest prevalence was in the 25-34-yearold age group. The mean age was 29.2 years. There were 54 patients $(75 \%)$ without prenatal care by trained health care personnel, and 18 patients $(25 \%)$ with prenatal care who had UCP and were treated in the labor and delivery facilities of University College Hospital, Ibadan, during the study period.

Table I Demographic data of incidence of umbilical cord prolapse in women with and without prenatal care

\begin{tabular}{llll}
\hline Age in years & Prenatal care & No prenatal care & Total \\
\hline $15-24$ & 5 & 11 & 16 \\
$25-34$ & 8 & 33 & 41 \\
$\geq 35$ & 5 & 10 & 15 \\
Total & $18(25 \%)$ & $54(75 \%)$ & 72 \\
\hline
\end{tabular}

Notes: Chi square: 1.55; Degree of freedom: 2; $P$-Value: 0.461 ; There is no statistical significant difference in the age group of women with and without prenatal care in regards to incidence of umbilical cord prolapse.
Table 2 shows mode of delivery and prenatal care status. Thirty-six (or $50 \%$ of cases) were delivered by emergency cesarean section, and nine (or 12.5\%) had assisted vaginal delivery. Spontaneous vaginal delivery was allowed in 12 cases $(16.7 \%)$ in which 10 fetuses were dead. Two live babies were delivered spontaneously vaginally before operative delivery could be carried out.

Table 3 shows neonatal outcomes between women with, and without, prenatal care. There were 29 perinatal deaths overall, with 25 perinatal deaths $(86.2 \%)$ occurring in women without prenatal care, compared with four perinatal deaths $(16.8 \%)$ in women with prenatal care. The perinatal mortality among women without prenatal care was higher; 25 (46.3\%) without prenatal care as compared with $4(22.2 \%)$ in women with prenatal care.

Table 4 shows the Apgar scores at 5 minutes of the 43 surviving babies and the prenatal status of their mothers. Twenty-one babies (49\%) had Apgar scores at 5 minutes of greater than 7, and did not require neonatal intensive care admission; this was almost equally divided between women with prenatal care and those without. However, 22 babies (51\%) had Apgar scores at 5 minutes of less than 7; most of them needed neonatal intensive care admission. Of these, 4 babies (18.2\%) were from mothers who had prenatal care, and 18 babies $(81.2 \%)$ from women who had not had prenatal care. There is a higher proportion of perinatal morbidity (defined by Apgar scores at 5 minutes of less than 7) in women with no prenatal care.

Table 5 shows the timing of perinatal death and the maternal prenatal status. A majority of the perinatal deaths - 22 in total or $76 \%$ - probably occurred before the arrival of the patients to the hospital, and were diagnosed at presentation. However, seven perinatal deaths (24\%) occurred

Table 2 Comparison of modes of delivery between women with prenatal care and without prenatal care with umbilical cord prolapse

\begin{tabular}{llll}
\hline Mode of delivery & Prenatal care & No prenatal care & Total \\
\hline $\begin{array}{l}\text { Emergency cesarean } \\
\text { section }\end{array}$ & 10 & 26 & 36 \\
$\begin{array}{l}\text { Forceps or vacuum } \\
\text { delivery }\end{array}$ & 4 & 5 & 9 \\
$\begin{array}{l}\text { Assisted vaginal breech } \\
\text { delivery }\end{array}$ & 1 & 6 & 7 \\
$\begin{array}{l}\text { Spontaneous vaginal } \\
\text { delivery }\end{array}$ & 2 & 10 & 12 \\
$\begin{array}{l}\text { Destructive operation } \\
\text { Total }\end{array}$ & 1 & 7 & 8 \\
\hline
\end{tabular}

Notes: Chi square: 3.5 ; degree of freedom: 4 and $P$-value: 0.478 ; There is no statistical significant difference in the mode of delivery between women with prenatal care and without prenatal care. 
Table 3 The perinatal outcome between women with prenatal care and without prenatal care

\begin{tabular}{llll}
\hline Perinatal outcome & $\begin{array}{l}\text { Prenatal } \\
\text { care }\end{array}$ & $\begin{array}{l}\text { No prenatal } \\
\text { care }\end{array}$ & Total \\
\hline $\begin{array}{l}\text { Surviving beyond } \\
\text { perinatal period }\end{array}$ & 14 & 29 & 43 \\
Perinatal death & 4 & 25 & 29 \\
Total & 18 & 54 & 72 \\
\hline
\end{tabular}

Notes: $P$-value: 061 , not statistically significant. The relative risk of perinatal death is $3.02,95 \% \mathrm{Cl}(0.879$ to 10.356$)$ at a $P$-value of 0.061 . However, there is no statistical significant difference of perinatal death between women who had inadequate prenatal visits compared with women who received adequate prenatal care. Abbreviation: $\mathrm{Cl}$ : Confidence interval.

in hospitalized patients. Among the perinatal deaths on arrival, $21(95.5 \%)$ occurred in women without prenatal care as compared to one perinatal death $(4.5 \%)$ in women with prenatal care.

\section{Discussion}

The presence of the umbilical cord in the birth canal or fornices, either by prolapse or presentation, is a potential obstetric catastrophe for the fetus, and a cause of significant concern to the mother, labor and delivery staff. However, awareness of high-risk patients in the prenatal clinic visits may help facilitate speedy diagnosis and delivery if prolapse occurs. Women with transverse, oblique or unstable lie should be offered elective admission to hospital at $37+6$ weeks of gestation, or sooner if there are signs of labor or suspicious of ruptured membranes. Even more so, women with noncephalic presentation and preterm prelabor rupture of the membranes should be offered admission. In-patient care will minimize delay in diagnosis and management of UCP. Labor or rupture of the membranes with a fetus in an abnormal lie is an indication for cesarean section. Bradycardia and variable decelerations of fetal heart rate are associated with cord prolapse, and their presence should prompt vaginal or speculum examination, regardless of gestational age, in order to diagnose UCP.

Table 4 Apgar scores of surviving babies between women with prenatal care and no prenatal care with umbilical cord prolapse

\begin{tabular}{llll}
\hline Apgar scores & $\begin{array}{l}\text { Prenatal } \\
\text { care }\end{array}$ & $\begin{array}{l}\text { No prenatal } \\
\text { care }\end{array}$ & Total \\
\hline $\begin{array}{l}\text { Apgar scores in } \\
5 \text { minutes } \geq 7\end{array}$ & $10(71.4 \%)$ & $11(37.9 \%)$ & $21(48.8 \%)$ \\
$\begin{array}{l}\text { Apgar scores in } \\
5 \text { minutes }<7\end{array}$ & $4(28.6 \%)$ & $18(62.1 \%)$ & $22(51.2 \%)$ \\
Total & 14 & 29 & 43 \\
\hline
\end{tabular}

Notes: The relative risk of perinatal morbidity and neonatal intensive care unit admission is $4.09,95 \% \mathrm{Cl}(1.03$ to 16.30$)$ at a $P$-value of $0.04 \mathrm{I}$. There is a statistical significant difference of Apgar scores at 5 minutes between babies of women with prenatal care and without prenatal care.

Abbreviation: $\mathrm{Cl}$ : Confidence interval
Table 5 Comparison of timing of perinatal death between women with prenatal care and without prenatal care with umbilical cord prolapse

\begin{tabular}{llll}
\hline $\begin{array}{l}\text { Timing of perinatal } \\
\text { death }\end{array}$ & $\begin{array}{l}\text { Prenatal } \\
\text { care }\end{array}$ & $\begin{array}{l}\text { No prenatal } \\
\text { care }\end{array}$ & Total \\
\hline $\begin{array}{l}\text { Perinatal death before } \\
\text { arrival in hospital }\end{array}$ & $\mathrm{I}$ & 21 & 22 \\
$\begin{array}{l}\text { Perinatal care in hospital } \\
\text { Total }\end{array}$ & 3 & 4 & 7 \\
\hline
\end{tabular}

Notes: The odds ratio of perinatal death before arrival in hospital is 0.0635 : $95 \%$ confidence interval $(0.0052$ to 0.776$)$ at $P$-value of 0.03 between women with prenatal care and without prenatal care. There is a statistical significant difference between women with prenatal care and without in regards to timing of perinatal death.

The incidence of UCP varies widely in many places. ${ }^{5,22}$ The prevalence of $0.47 \%$ ( 1 in 212 deliveries) in this study is comparable to other studies of 1 in 385,1 in 277 , and 1 in 426 deliveries. ${ }^{5,12,22}$ It also falls within the range of 1 in 200-500 deliveries reported in similar studies elsewhere. ${ }^{8,9,23}$ Moreover, this study showed that the risk of UCP was three times higher among women with inadequate or no prenatal care as compared with those who had routine prenatal care visits.

When cord prolapse occurs, immediate delivery is the ideal if the fetus is alive and viable. ${ }^{7,20,21}$ The choice of mode of delivery and the promptness of attention are extremely important, since both factors are important determinants in the fetal and maternal outcome. ${ }^{24}$

In this study 50 fetuses (69.4\%) were alive at the time of presentation; $36(72.0 \%)$ were delivered by emergency cesarean section, $9(18.0 \%)$ had assisted vaginal delivery by obstetric forceps or vacuum extraction. Cesarean section has been widely advocated in cases of UCP, especially if the fetus is alive, so as to reduce perinatal morbidity and mortality. ${ }^{10,13,25}$ The cesarean section rate in this study was $50 \%$, as against the hospital cesarean section rate during the study period of $18.5 \%$. These cases were operated on either because the cervix was not fully dilated ${ }^{10}$ to allow assisted vaginal delivery, or for strictly obstetric indications. ${ }^{25}$ Though the cesarean section rate for cord prolapse in this study is about three times that of hospital rate for same period, it is comparable to cesarean section rates for UCP in other studies. ${ }^{26}$

There is still a place for vaginal delivery in UCP in selected cases when the fetus is alive, especially if the cervix is fully dilated and delivery is imminent. This is well demonstrated in this study where nine deliveries $(12.5 \%)$ were accomplished by assisted vaginal delivery. This mode of delivery should be considered as alternative to cesarean section when the condition is suitable without compromising 
the mother and the baby. This is of utmost importance in developing countries where is there is strong aversion to cesarean section in a majority of the patients, prolonged decision-to-delivery interval, and high rates of loss to follow up. Some of the cesarean section patients may choose to use mission homes and traditional birth attendants in their subsequent pregnancies for prenatal cares and deliveries in order to avoid repeat cesarean sections. These decisions may result in uterine rupture and its associated sequelae.

Spontaneous vaginal delivery occurred in 12 cases $(16.7 \%)$ in this series because most of the fetuses were dead, and there were no contraindications to vaginal delivery.

The prognosis for the fetus depends on a number of factors, which include the gestational age, duration of cord prolapse before intervention, stage of labour, rapidity, efficiency of first aid, definitive management, and effective neonatal intensive care..$^{20,27-29}$ The risk of perinatal morbidity and neonatal intensive care unit admission (as judged by the presence of 5-minute Apgar scores of less than 7) was statistically significantly higher among women without prenatal care, as compared with women with prenatal care (OR 4.09, 95\% CI: 1.03 to $16.30 ; P$-value $=0.041$ ).

The perinatal mortality rate varies between patients with prenatal care and those without prenatal care. The overall perinatal death in this study was 29 , of which $25(86.2 \%)$ occurred among women without prenatal care while $4(13.8 \%)$ occurred in women with adequate prenatal care visits. However, there was no statistically significant difference in the risk of perinatal death between women with prenatal care and those without (OR 3.02, 95\% CI: 0.879 to 10.356; $P$-value $=0.061$ ). The proportion of perinatal death among viable fetuses with UCP was $40.3 \%$ in this study. Hence, the perinatal mortality rate in the study population was 403 per 1000 total births; five times higher than the overall hospital perinatal mortality rate of 80 per 1000 total births during the study period. ${ }^{7}$ The perinatal mortality rate was higher among women without prenatal care (463 per 1000 total births), as compared to women with adequate prenatal care (222 per 1000 total births).

The risk of perinatal death before arrival at hospital is less in women with prenatal care than in women without prenatal care (OR 0.0635; 95\% CI: 0.0052 to 0.776 ; $P$-value $=0.03$ ). Women with adequate prenatal care are more likely to be knowledgeable about the danger signals of pregnancy, and present early to the hospital as soon as they sense that there are problems. However, women without prenatal care may try other unorthodox options, such as mission homes and/ or uncertified traditional birth attendants in the community, before presenting to the hospital. This may explain why they have a higher proportion of perinatal death on arrival at the hospital, as compared with women who had adequate prenatal care.

Debriefing should be offered to all women with UCP by a suitably trained professional to reduce psychological disorders such as postnatal depression, post-traumatic stress disorders, or fear of further childbirth. They should also be counselled to utilize prenatal services and seek help whenever necessary in their next pregnancy.

\section{Conclusion}

It is obvious from this study that the risk of UCP is higher among women who have poor prenatal care, constituting $75 \%$ of the study population. Therefore, provision of efficient, accessible, and affordable prenatal care services would help reduce the incidence of cord prolapse in our clinical environment, and also decrease the associated perinatal morbidity and mortality.

The prevention and reduction of perinatal morbidity and mortality associated with UCP depends on making antenatal care services readily and easily available in areas where they are most needed. Therefore the various conditions that predispose to UCP should be identified early during prenatal visits, where prompt and appropriate remedies can be instituted. Most women who did not receive prenatal care often delayed seeking help when UCP occured. However, women who received prenatal care often present promptly to the hospital, where they usually received prenatal care, or to the nearest available health facilities to seek help.

An early resort to cesarean section, proper and effective prenatal care, and properly supervised hospital delivery are recommended to reduce or prevent the complications associated with cord prolapse.

\section{Disclosure}

The authors report no conflicts of interest in this work.

\section{References}

1. Brown RD Jr, Trupin SR, Brown ML. Umbilical cord prolapse: a contemporary look. J Reprod Med. 1991;36(6):13-14.

2. Duchatel F, Hamm P, Oury JF. The history of the drop prolapse of the umbilical cord. Rev Fr Gynecol Obstet. 1988;83(7-9):561-567.

3. Johnson RL, Anderson JC, Irsik RD, Goodlin RC. Duplex ultrasound diagnosis of umbilical cord prolapse. J Clin Ultrasound. 1987;15(4):282-284.

4. Katz Z, Shoham Z, Lancet M, Blickstein I, Mogilner BM, Zalel Y. Management of labor and umbilical cord prolapse: a 5-years study. Obstet Gynaecol. 1988;72(2):278-281.

5. Murphy DJ, Mackenzie I. The mortality and morbidity associated with umbilical cord prolapse. Br J Obstet Gynaecol. 1995;102(10):826-830

6. Walraven G, van Roosmalen J. Umbilical cord prolapse in rural Africa. Lancet. 1996;347(9003):773. 
7. Enakpene CA, Omigbodun AO, Arowojolu AO. Perinatal mortality following umbilical cord prolapse. Int J Gynecol Obstet. 2006;95(1): 44-45.

8. Dare FO, Owolabi AT, Fasuba OB, Ezechi OC. Umbilical cord prolapse: a clinical study of 60 cases seen at the Obafemi Awolowu University Teaching Hospital, Ile-Ife. East Afr Med J. 1998;75(5):308-310.

9. Kahana B, Sheiner E, Levy A, Lazer S, Mazor M. Umbilical cord prolapse and perinatal outcomes. Int J Gynecol Obstet. 2004;84(2):127-132.

10. Critchlow CW, Leet TL, Benedetti TJ, Daling JR. Risk factors and infant outcomes associated with umbilical cord prolapse: a population - based case control-control study among births in Washington State. Am J Obstet Gynecol. 1994;170(2):613-618.

11. Usta IM, Mercer BM, Sibai BM. Current obstetrical practice and umbilical cord prolapse. Am J Perinatol. 1999;16(9):479-484.

12. Uygur D, Kis S, Tuncer R, Ozcean FS, Erkaya S. Risk factors and infant outcomes associated with umbilical cord prolapse. Int J Gynecol Obstet. 2002; 78(2):127-130.

13. Yla-Outinen A, Henonen PK, Tuimala R. Predisposing and risk factors of umbilical cord prolapse. Acta Obstet Gynecol Scand. 1985;64(7):567-570.

14. Bozhinova S, Porozhanova V, Popovski K. The significance of the problem of umbilical cord prolapse during delivery. Akush Geneko (Sofiia). 1998;37(1):10-12.

15. Barrett JM. Funic reduction for the management of umbilical cord prolapse. Am J Obstet Gynecol. 1991;165(3):654-657.

16. Bustos JC. Vesical filling for the management of umbilical cord prolapse. Rev Chil Obstet Ginecol. 1993;58(4):277-280.

17. Runnebaum IB, Katz M. Intrauterine resuscitation by rapid urinary bladder instillation in a case of occult prolapse of an excessively long umbilical cord. Eur J Obstet Gynecol Reprod Biol. 1999;84(1): 101-102.

18. Poetker DM, Rijhsinghani A. Fetal survivals after umbilical cord prolapse for than three days. A case report. J Reprod Med. 2001;46(8): 776-778.
19. Faiz SA, Habib FA, Sporrong BG, Khalil NA. Results of delivery in umbilical cord prolapse. Saud Med J. 2003;24(7):754-757.

20. Orhue AA, Unuigbe JA. Determinant factors in foetal mortality associated with umbilical cord prolapse. Asia Oceania J Obstet Gynecol. 1984;10(1):75-82.

21. Katz Z, Lancet M, Borenstein R. Management of labor with umbilical cord prolapse. Am J Obstet Gynecol. 1982;142(2):239-241

22. Levy H, Meier PR, Makowski EL. Umbilical cord prolapse. Obstet Gynecol. 1984;64(4):499-502.

23. Dilbaz B, Ozturkoglu E, Dilbaz S, Ozturk N, Sivaslioglu AA, Hebral A. Risk factors and perinatal outcomes associated with umbilical cord prolapse. Arch Gynecol Obstet. 2006;274(2):104-107.

24. Nizard J, Cromi A, Molendijk H, Arabin B. Nenontal outcomes following prolonged umbilical cord prolapse in preterm premature rupture of membranes. Br J Obstet Gynaecol. 2005;112(6):833-836.

25. Caspi E, Lotan Y, Schreyer P. Prolapse of the cord: reduction of perinatal mortality by bladder instillation and cesarean section. Isr J Med Sci. 1983;19(6):541-545

26. Siassako D, Hasafa Z, Sibanda T, et al. Retrospective cohort study of diagnsosis-delivery interval with umbilical cord prolapse: the effect of team training. Br J Obstet Gynaecol. 2009;116(8):1089-1096.

27. Katz Z, Lancet M, Dgani R, Ben-Hur H, Zalel Y. The beneficial effects of vacuum extraction of the fetus. Acta Obstet Gynecol Scand. 1982;61(4): $337-340$.

28. Ginosar Y, Weiniger C, Elchalal U, Davidson E. Emergency cesarean delivery for umbilical cord prolapse: the head-down, kneechest prone position for the spinal anesthesia. Can J Anesth. 2008; 55(9):612-615.

29. Khan RS, Naru T, Nizami F. Umbilical cord prolapse- a review of diagnosis to delivery interval on perinatal and maternal outcomes. J Pak Med Assoc. 2007;57(19):487-491.
International Journal of Women's Health

\section{Publish your work in this journal}

The International Journal of Women's Health is an international, peerreviewed open-access journal publishing original research, reports, reviews and commentaries on all aspects of women's healthcare including gynecology, obstetrics, and breast cancer. Subject areas include: Chronic conditions (migraine headaches, arthritis, osteoporosis);

\section{Dovepress}

Endocrine and autoimmune syndromes; Sexual and reproductive health; Psychological and psychosocial conditions. The manuscript management system is completely online and includes a very quick and fair peer-review system. Visit http://www.dovepress.com/ testimonials.php to read real quotes from published authors. 